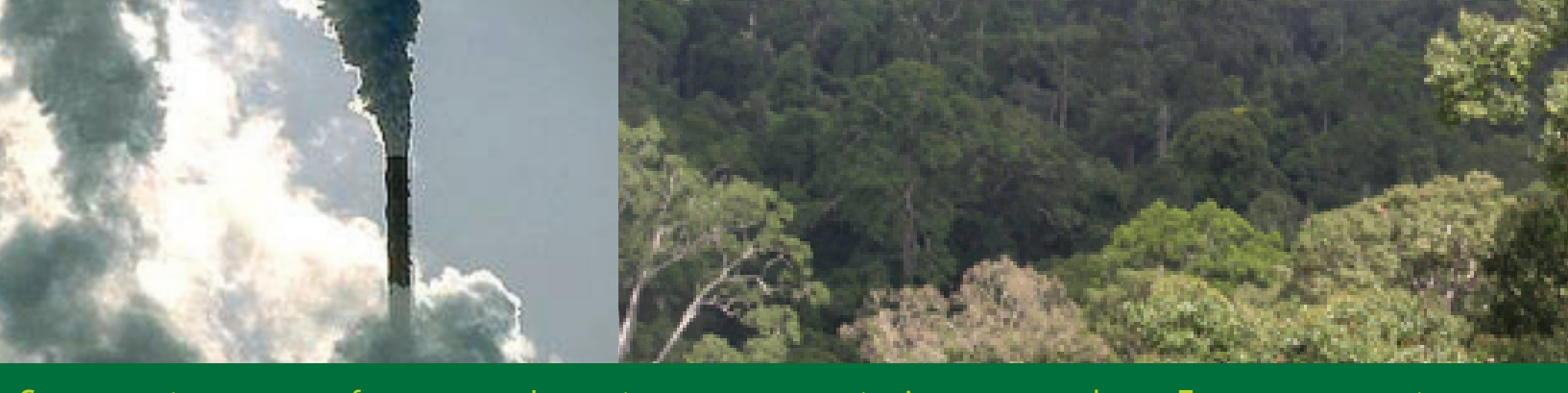

$c$ e $n$ t e r

f 0 r

I $n$ t e r n

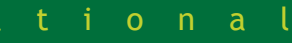

o $r$ e s t $r y$

R e s e a $r$ c $h$

Environmental Services and Sustainable Use of Forests Programme
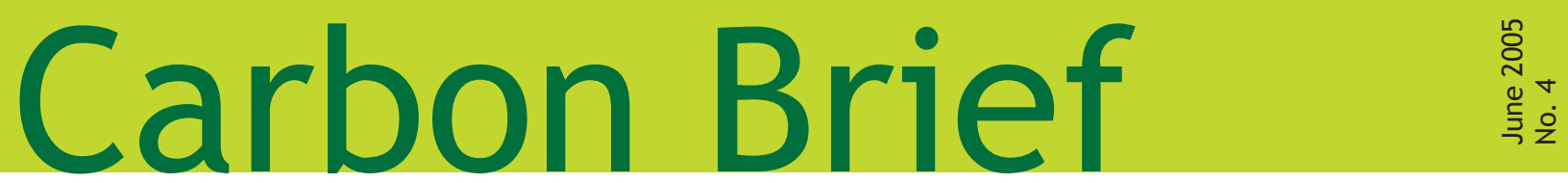

\title{
A/R Clean Development Mechanism Project Activities: Development of PDD
}

- General description of project activity

- Baseline methodology

- Monitoring methodology and plan

- Estimation of net removal by sinks of anthropogenic greenhouse gases

- Environmental impacts

- Socio-economic impacts

- Stakeholders' comments

The project design document (PDD) has to be developed by the participants (often termed as developers) that consist of investor and host. It can be facilitated by intermediaries. This policy brief outlines the structure of the PDD and provides information on how to fill it out. It is based on guidelines that may be downloaded from http://unfccc.int/cdm. This version was prepared in connection with the technical assistance provided by the Asian Development Bank to the Government of Indonesia, Gol (Project code: TA 4137-INO).

\section{A. General description of project activity}

1. Project title

2. Short description of project activity:

Describe the purpose of the project and the view project participants have of its contribution to sustainable development.

3. Project participants:

List the project participants (private and/or public entities) involved in the project activity (details to be attached as Annex 1).

4. Technical description of project activity:

4.1 Project location:

List host party/parties, region/state/province, city/town/community, etc.

4.2 Details of geographical location and project boundary, including information allowing unique identification of the project activity:

Describe the present environmental conditions of the area including climate, hydrology, soils, ecosystems, and the possible presence of rare or endangered species and their habitats. The 'project boundary' geographically delineates the afforestation and reforestation clean development mechanism (A/R CDM) 
project activity under the control of the project participants. If an A/R CDM project activity contains more than one discrete area of land,

- each discrete area of land should have an unique geographical identification and

- the boundary should be defined for each discrete area and should not include the areas in between these discrete areas of land.

4.3 Species and varieties selected:

Scientific names may be used.

4.4 Specification of the greenhouse gases (GHG) whose emissions will be part of the proposed A/R CDM project activity:

Specify the GHG that are expected to be emitted as a result of the implementation of the proposed A/R CDM project activity, for example, inter alia, emissions from soil preparation, from the use of machinery, and from the use of fertilisers.

4.5 Carbon pools selected:

In calculating the baseline net GHG removals by sinks, project participants shall account for all significant changes in carbon pools and/or emissions of GHG measured in units of $\mathrm{CO}_{2}$ equivalents by the sources that are increased as a result of the implementation of the proposed A/R CDM project activity, while avoiding double counting.

4.6 Compliance with the definition for afforestation or reforestation:

Specify how the project fulfils the definition of afforestation or reforestation as provided in the glossary of terms (see Carbon Brief \#2). In order to define afforestation or reforestation, project participants shall follow the definition for 'forest' selected by $\mathrm{Gol}$, which specifies plots of at least 0.25 ha in size and with a minimum canopy cover of 30 percent from trees that at the end of their growing period potentially reach at least $5 \mathrm{~m}$ in height.

4.7 Description of legal title to the land, current land tenure and land use and rights of access to the sequestered carbon

4.8 Type(s) of A/R CDM project activity:

Use the list of types of $A / R$ CDM project activities and of registered A/R CDM project activities by type available on the United Nations Framework Convention on Climate Change UNFCCC CDM web site at http://unfccc.int/cdm. If no suitable type(s) of $A / R$ CDM project activities can be identified, suggest a new type descriptor and its definition, being guided by relevant information on the UNFCCC CDM web site.

4.9 Technology to be employed by the project activity:

Include a description of the environmentally safe and sound technologies and knowhow that will be employed by the project, specifying, if any, those to be transferred Indonesia.

4.10 Approach for addressing impermanence:

In accordance with A/R CDM modalities and procedures, specify the issuance of certified emission reduction (CER) [either temporary (tCER) or long-term (ICER)] to address impermanence.

4.11 Duration of project activity/crediting period:

a. Starting date of activity and of (first) crediting period, including a justification:

Give the date on which implementation or real action of project activity begins, resulting in actual net GHG removals by sinks. Project activities should start after 1 January 2000 and documentation needs to be provided at the time of registration.

b. Expected operational lifetime of project activity:

State the expected operational lifetime of the proposed A/R CDM project activity in years and months as appropriate.

c. Choice of crediting period and related information:

State whether the proposed A/R CDM project activity will use a renewable or a fixed crediting period.

- Renewable crediting period, if selected:

Each crediting period shall be a maximum of twenty (20) years and may be renewed at most two times provided that, for each renewal, a designated operational entity determines and informs the executive board that the original project baseline is still valid or has been updated taking into account new data, if applicable. 
- Starting date of the first crediting period:

State starting date in the format $\mathrm{DD} / \mathrm{MM} / \mathrm{YY}$.

- Length of the first crediting period:

State duration in years and months.

- Fixed crediting period, if selected:

Fixed crediting period shall be at most thirty (30) years.

- Starting date:

State starting date in the format $\mathrm{DD} / \mathrm{MM} / \mathrm{YY}$.

- Length:

State duration in years and months.

5. Brief explanation of how the project activity achieves the net anthropogenic GHG removals by sinks, including why these would not occur in the absence of the project activity, taking into account national and/or sectoral policies and circumstances:

Briefly explain how net anthropogenic GHG removals by sinks are to be achieved (details to be provided in section $B$ ) and provide the estimate of the anticipated total net anthropogenic $G H G$ removals by sinks in tonnes of $\mathrm{CO}_{2}$ equivalent as determined in section $E$ (max. one page).

Estimated amount of net anthropogenic GHG removals by sinks over the chosen crediting period:

Provide the total estimation of net anthropogenic GHG removals by sinks as well as annual estimates for the chosen crediting period.

6. Public funding of project activity:

If public funding from parties listed in Annex I is involved, provide in Annex 2 information on sources of such funding. Parties providing such funding shall affirm that it does not result in a diversion of official development assistance (ODA).

\section{B. Baseline methodology}

1. Title and reference of the approved baseline methodology applied to the project activity: Refer to http://unfccc.int/cdm for the title and reference list as well as the details of approved baseline methodologies. Please note that the table 'Baseline Information' contained in Annex 3 is to be prepared in parallel with the remainder of this section.

2. Justification of choice of methodology and its applicability to the project activity: Justify the choice of methodology by showing that the proposed A/R CDM project activity meets the applicability conditions under which the methodology is applicable.

3. Description of how the methodology is applied to the project activity:

Explain the basic assumptions of the baseline methodology in the context of the proposed A/R CDM project activity and show that the key methodological steps are followed in determining the baseline scenario for the proposed A/R CDM project activity. Provide the key information and data used to determine the baseline scenario (variables, parameters, data sources, etc.) in table form.

4. Description of how the actual net GHG removals by sinks are higher than those that would have occurred in the absence of the registered project activity:

Explain how and why this project provides additional removal and therefore differs from the baseline scenario in accordance with the selected baseline methodology. Include (1) a description of the baseline scenario determined by applying the methodology, (2) a description of the project scenario, and (3) an analysis showing why the baseline net GHG removals by sinks scenario would likely lie below actual net anthropogenic GHG removals by sinks in the project scenario.

5. Detailed baseline information, including the date of completion of the baseline study and the name(s) of person(s)/entity(ies) determining the baseline:

Attach detailed baseline information in Annex 3. Provide date of completion in DD/MM/ YYYY format. Provide contact information and indicate if the person/entity is also a project participant listed in Annex 1. 


\section{Monitoring methodology and plan}

1. Methodology:

Refer to http://unfccc.int/cdm for the names, references, and details of approved methodologies. If a national or international monitoring standard has to be applied to monitor certain aspects of the proposed A/R CDM project activity, identify this standard and provide a reference to the source where a detailed description of the standard can be found.

2. Justification:

Justify the choice of methodology by showing that the proposed A/R CDM project activity and its context meet the conditions under which the methodology is applicable.

3. Monitoring (in the form of a table):

3.1 Actual net GHG removals by sinks data (monitored data shall be archived for two years following the end of the (last) crediting period)

- Describe data to be collected or used in order to monitor the verifiable changes in carbon stock in the carbon pools within the project boundary resulting from the project activity, and how these data will be archived.

- Describe data to be collected or used in order to monitor the GHG emissions by the sources, measured in units of $\mathrm{CO}_{2}$ equivalent, that are increased as a result of the implementation of the proposed A/R CDM project activity within the project boundary, and how these data will be archived.

- Describe formulae and/or models used to monitor the estimation of actual net GHG removals by sinks. (Be consistent with the ones outlined in the description of the baseline methodology.)

- Describe formulae and/or models used to monitor the estimation of the verifiable changes in carbon stock in the carbon pools within the project boundary (for each carbon pool in units of $\mathrm{CO}_{2}$ equivalent).

- Describe formulae and/or models used to monitor the estimation of GHG emissions by the sources, measured in units of $\mathrm{CO}_{2}$ equivalent, that are increased as a result of implementation of the project activity within the project boundary. (Be consistent with the ones outlined in the description of the baseline methodology.)

3.2 As appropriate, describe relevant data necessary for determining the baseline net GHG removals by sinks and how such data will be collected and archived. (Monitored data shall be archived for two years following the end of the (last) crediting period.)

- Describe formulae and/or models used to monitor the estimation of the baseline net GHG removals by sinks. (Be consistent with the ones outlined in the description of the baseline methodology.)

4. Treatment of leakage in the monitoring plan:

Indicate whether leakage will be directly or indirectly monitored. If leakage is not monitored during the implementation of the project activity, please explain rationale behind it.

4.1 If applicable, describe the data and information that will be collected in order to monitor leakage of the project activity. (Monitored data shall be archived for two years following the end of the (last) crediting period.)

4.2 Describe formulae and/or models used to estimate leakage for each GHG, source, carbon pool, in units of $\mathrm{CO}_{2}$ equivalent. (Be consistent with the ones outlined in the description of the baseline methodology.)

4.3 Specify procedures for periodic review of implementation of activities and measures to minimize leakage.

5. Describe formulae and/or models used to estimate net anthropogenic GHG removals by sinks for the proposed A/R CDM project activity. (Be consistent with the ones outlined in the description of the baseline methodology.)

6. Describe quality control $(\mathrm{QC})$ and quality assurance (QA) procedures undertaken for data monitored.

7. Describe the operational and management structures the project operator will implement in order to monitor actual GHG removals by sinks and any leakage generated by the proposed A/R CDM project activity.

8. Name of person/entity determining the monitoring methodology:

Provide contact information and indicate if the person/entity is also a project participant listed in Annex 1 of this document. 


\section{Estimation of net anthropogenic GHG removals by sinks}

1. Estimate the actual net GHG removals by sinks:

Provide estimated sum of verifiable changes in carbon stocks minus the increase in emissions measured in units of $\mathrm{CO}_{2}$ equivalent by the sources that are increased as an attributable result of the implementation of the proposed A/R CDM project activity within the project boundary (for each gas, pool, source, formulae/algorithm, in units of $\mathrm{CO}_{2}$ equivalent).

2. Estimated baseline net GHG removals by sinks:

Give estimates for each carbon pool and source in units of $\mathrm{CO}_{2}$ equivalent.

3. Estimated leakage:

Provide estimate of any leakage, defined as the increase of anthropogenic emissions by sources of GHG that occurs outside the project boundary and that is measurable and attributable to the proposed A/R CDM project activity. Estimates should be given for each gas and source in units of $\mathrm{CO}_{2}$ equivalent.

4. Net anthropogenic GHG removals by sinks of the proposed A/R CDM project activity: The sum of D.1 minus D.2 minus D.3.

5. Table providing values obtained when applying formulae should be included. The ex post facto calculation of baseline removal rates may only be used if proper justification is provided. Notwithstanding, baseline removal rates shall also be calculated ex ante facto and reported in the A/R CDM-PDD.

\section{E. Environmental impacts of proposed A/R CDM project activity}

The analysis of environmental impacts, including impacts on biodiversity and natural ecosystems and impacts outside the project boundary, should be documented. If any negative impact is considered significant by project participants or host Party, it should be stated that project participants did undertake an environmental impact assessment in accordance with the procedures required by the host Party. Monitoring plan and remedial measures to address significant impacts should be described.

This analysis should include, if applicable, information on, inter alia, hydrology, soils, risk of fires, pests, and diseases. Please attach the relevant documentation to the CDM-PDD.

\section{F. Socio-economic impacts of proposed_A/R CDM project activity}

1. Documentation of the analysis of socio-economic impacts, including impacts outside the project boundary of the proposed A/R CDM project activity:

This analysis should include, if applicable, information on, inter alia, local communities, indigenous peoples, land tenure, local employment, food production, cultural and religious sites, and access to fuelwood and other forest products. Please attach the documentation to the A/R CDM PDD.

2. If any negative impact is considered significant by the project participants or the host Party, it should be stated that project participants did undertake a socio-economic impact assessment in accordance with the procedures required by the host Party, including conclusions and all references to support documentation.

Attach the documentation to the A/R CDM PDD.

3. Describe planned monitoring and remedial measures to address significant impacts referred to in section above.

\section{G. Stakeholders' comments}

1. Brief description of how comments by local stakeholders have been invited and compiled: Describe the process by which comments by local stakeholders have been invited and compiled. An invitation for comments by local stakeholders shall be made in an open and transparent manner, in a way that facilitates comments from local stakeholders to be received and allows 
for a reasonable time for comments to be submitted. In this regard, project participants shall describe an A/R CDM project activity in a manner that allows local stakeholders to understand the proposed A/R CDM project activity, taking into account confidentiality provisions of the CDM modalities and procedures.

2. Summary of the comments received:

Identify stakeholders that have made comments and provide a summary of these comments.

3. Report on how due account was taken of any comments received:

Explain how due account has been taken of comments received from stakeholders.

In the PDD the following Annexes should be provided by project developers :

Annex 1. Contact Information on Participants in the Project Activity

Annex 2. Information Regarding Public Funding

Annex 3. Baseline Information

Annex 4. Monitoring Plan

Box 1

Simplified PDD for small-scale A/R CDM project activities

The guideline for small-scale A/R CDM PDD is almost identical. There is a separate section on 'Duration of project activity' but none on 'Socio-economic impacts'. Section A5 is not needed and replaced by 'Confirmation that the small-scale project activity is not a debundled component of a larger project activity'. The annexes are only for 'Information on Participants in the Project Activity' and 'Information Regarding Public Funding'. Detailed guidelines may be obtained from http://unfccc.int/cdm/ssc.htm.

This document is published in connection with the technical assistance provided by the Asian Development Bank (ADB) to the Government of Indonesia (Gol) on Carbon Sequestration Project through Clean Development Mechanism (Code: TA 4137-INO).
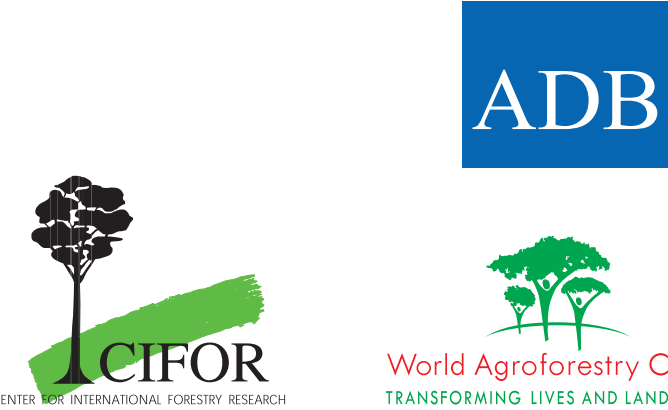

World Agroforestry Centre TRANSFORMING LIVES AND LANDSCAPES
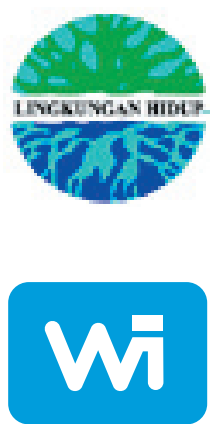

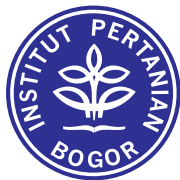

\section{CIFOR}

Center for International Forestry Research

Jalan CIFOR, Situ Gede, Bogor Barat 16680, Indonesia

Tel: +62 251622622 Fax: +62 251622100 E-mail: cifor@cgiar.org www.cifor.org

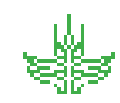

CGIAR

F U T URE HARY/EST 